\title{
DHCR24 Promotes Melanoma Stem-Like Cells Formation and Mediates Vemurafenib Resistance by Accumulating 27-Hydroxycholesterol
}

\section{Feiliang Zhong}

Tianjin University

Tingting Chen

Guangdong Medical University

Jia Liu

Tianjin University

Ying Wang

Tianjin University

Mingdong Yao

Tianjin University

Bo Li ( $\square$ lib028@tju.edu.cn )

Tianjin University

\section{Research Article}

Keywords: DHCR24, 27-HC, Melanoma Stem-like Cells, AKT Pathway, Drug Resistance

Posted Date: December 16th, 2021

DOI: https://doi.org/10.21203/rs.3.rs-1148681/v1

License: (c) (i) This work is licensed under a Creative Commons Attribution 4.0 International License. Read Full License 


\section{Abstract}

Background: Melanoma is the most serious skin cancer with gradually increased incidence and poor prognosis mainly as the result of cancer stem cell (CSC) expansion and drug resistance. Some studies have suggested that dysregulated cholesterol homeostasis increasing tumorigenicity and metastasis in cancers. In the present study, our objective was to elucidate the contribution of 24-Dehydrocholesterol reductase (DHCR24) towards melanoma progression and drug resistance.

Methods: Immunohistochemistry and HE staining were performed for determing the expression of DHCR24 in melanoma patients, lentivirus perturbation and functional assays were used to evaluate the ability of turmorigenesis of DHCR24 altered melanoma cells and melanoma stem-like cells. RNA sequencing (RNA-seq) and targeted metabolomics were carried out for identifying metabolites which contributes melanoma stem-like cell expansion and vemurafenib treatment resistance.

Results: DHCR24 was over-expressed in melanoma patients while knockdown of DHCR24 blocked melanoma cells in S phase and lead to significant inhibition in proliferation and migration. Meanwhile, forced expression of DHCR24 promotes the growth of melanoma cells in xenograft mice. We further demonstrated that DHCR24 promotes the proliferation of melanoma stem-like cell populations by activating Rap1/AKT signaling and result in accumulation of cellular 27-Hydroxycholesterol (27-HC) contents. Next, we validated that both CYP27A1 and 27-HC administration contributed to melanoma stem-like cells formation and vemurafenib resistance through AKT-308/309 phosphorylation.

Conclusions: Our data confirmed the oncogenic role of DHCR24 in melanoma stem-like cells proliferation and vemurafenib resistance by regulating $27-\mathrm{HC}$. These findings established the basis of targeting DHCR24 as a potential therapeutic target for advanced melanoma.

\section{Background}

Melanoma is the most serious skin cancer with gradually increased incidence in the past few decades [1]. It counts for approximately $1.7 \%$ cases of all newly diagnosed primary malignancies and $0.7 \%$ cancer deaths every year in the world. Once metastasis occurs, the prognosis of melanoma patients is extremely poor. The five-year survival rate for metastatic melanoma has been only $15-20 \%$ before the remarkable development of both targeted and immunotherapy [2, 3]. Although we have achieved a number of important scientific milestones, much more work remains to be done in malignant melanoma. V600E mutation on B-Raf proto-oncogene, serine/threonine kinase (BRAFV600E) is the most common driver mutation in melanoma patients. It leads to constitutive activation in mitogen-activated protein kinase (MAPK) signaling to support cell proliferation [4]. The development of BRAFV600E inhibitors (vemurafenib or dabrafenib) and MEK inhibitors (cobimetinib or trametinib) have greatly improved survival rate of advanced melanoma patients, however, plenty of patients suffered relapse approximately one year later due to drug resistance [5-8]. Cancer stem cells (CSCs) are rared population in cancer cells that retain the capacity of self-renewal, differentiation and initiation of tumor formation. A growing body 
of evidences reveal that CSCs are contributed to tumor metastasis, relapse and resistance to therapy [911]. Thus, deciphering the limiting factors that regulate the properties of CSCs is pressing needed for developing promising therapeutic strategies to eliminate melanoma recurrence.

Cholesterol is associated with tumorigenesis, especially in subtypes of upregulated mevalonate pathway. Oncogenic signals enable cancer cells to synthesize their own cholesterol to support rapid proliferation. Patient-derived gene expression analysis demonstrated that cholesterol biosynthesis was associated with tumorigenesis of breast cancer, sarcoma, melanoma and leukemia [12]. However, epidemiologic studies make contradictory conclusions regarding the use of statins, HMG-CoA reductase (HMGCR) inhibitor, and risk of cancer development. Preclinical investigations show that statins directly inhibit development and progression in cell and animal models of prostate and pancreatic cancer $[13,14]$. However, a great body of clinical meta-analysis failed to support the protective effect of statin on cancer $[15,16]$. One of the possibilities of that is off-target. It has been reported that statin-dependent enhancement of mitochondrial membrane potential in cancer cells is independent of cholesterol content [17]. In addition, due to the great need for rapid growth of cancer cell, detection of intracellular cholesterol content may be more reasonable than serum cholesterol [18]. More importantly, various cholesterol metabolites acts promotion or suppression role in cancers depending on cancer types and stage $[19,20]$. Thus, deciphering the key mediators involved in dysregulation of metabolism in certain context could provide novel therapeutic targets and highlight the importance of metabolism reprogramming in tumorigenesis.

Process of cholesterol metabolism generates numerous metabolites and biological activity molecules that involved in physiological processes and specific biological responses. 27-Hydroxycholesterol (27-HC) promotes breast cancer cell proliferation, invasion, and migration by activating with liver Tumor $\mathrm{X}$ receptor (LXR) while 25-Hydroxycholesterol (25-HC) shows anti-tumor activity in gastric cancer [2125]. The different functions of cholesterol metabolites raise the question of how to interfere with the metabolic pathway, and at which steps in cancer treatment. It has been reported that cholesterol and its metabolites also contribute to cancer stem-like cell populations in cancer progression by providing energy and proliferation signals [26-28]. However, the role of metabolic reprogramming, especially the linking between metabolic abnormality of cholesterol and CSCs, is not well elucidated yet. In this study, we aim to uncover the key components involved in the dysregulation of metabolism in melanoma stem-like cells looking forward to provide novel therapeutic targets of advanced melanoma.

Besides HMG-CoA Reductase (HMGCR), the first rate-limiting enzyme for cholesterol synthesis in the conversion of HMG-CoA to mevalonate, many other key enzymes in cholesterol biosynthesis have been reported to be involved in the initiation and metastasis of hepatocellular carcinoma and breast cancer [29, 30]. 3 beta-Hydroxysterol Delta (24)-reductase (DHCR24) catalyzes the ultimate step of cholesterol biosynthesis, which seems to have both cholesterol synthesizing and anti-apoptotic activities. As mediator of Ras-induced senescence, DHCR24 binds the p53 amino terminus and displaces the E3 ubiquitin ligase Mdm2 from p53, resulting in p53 accumulation [31]. DHCR24 is also implicated in numerous diseases, including tumors. It has been reported that inhibition of DHCR24 in pregnant mice caused teratogenic pups by desmosterol, zymosterol accumulation and mutations in the dhcr24 result in 
desmosterolosis, an autosomal recessive disease that is characterized by developmental and growth retardation [32, 33]. Furthermore, due to the inhibition of caspase-3, the decreased expression of DHCR24 is related to the increased apoptosis in adrenocortical cells, which is also found in the temporal cortex of Alzheimer's disease patients[34, 35]. In prostate cancer, DHCR24 is lower expressed in advanced tumors than early tumors and normal tissues and force expressed DHCR24 inhibits the cell growth $[36,37]$. Moreover, DHCR24 promotes the growth of CSC-like population via activation of Hedgehog pathway in breast cancer and protects melanoma cells from apoptosis, suggesting the role of tumorigenesis and potentials as therapeutic target [38-40]. In present study, we observed that DHCR24 promoted the growth of melanoma cells in xenograft mice and contributed to vemurafenib resistance by enhancement of melanoma stem-like cell populations proliferation. Additionally, DHCR24 activated Rap1 and induced 27-Hydroxycholesterol (27-HC) accumulation in melanoma cells. These findings established the basis for targeting DHCR24 as a potential treatment strategy for advanced melanoma.

\section{Materials And Methods}

\section{Cell culture and chemicals}

Human malignant melanoma cell lines A375 and embryonic kidney cell lines 293T cells were obtained from Cell Resource Center of Peking Union Medical College (IBMS, CAMS/PUMC). Human malignant melanoma cell lines A2058 was kindly provided by Dr. Fang from the Beijing Institute of Genomics. Cells were grown in high-glucose DMEM medium (Gibco) supplemented by $100 \mathrm{U} / \mathrm{ml}$ penicillin and $100 \mu \mathrm{g} / \mathrm{ml}$ streptomycin (TransGen Biotech.), and $10 \%$ fetal bovine serum (FBS) (Gibco) at $37^{\circ} \mathrm{C}$ with $5 \% \mathrm{CO}_{2}$.

\section{Construction of DHCR24 overexpression and shRNA constructs}

The pCDH-DHCR24 plasmid was constructed as follows, DHCR24 was amplified by reverse transcriptionPCR using mRNA from A2058 cells, with the forward primer (5'-

gcgttctagagctagcgCCgccaccATGGAGCCCGCCGTGTCGCT-3') and reverse primer (5'-

atCAGGCTGATCAGCGGGTTTAAACTCAGTGCCTGGCGGCCTTGCAG-3') including 25 bp homology arm with pCDH区the PCR product and pCDH (digested with EcoR1 and BamH1) fragments were then joined through Gibson assembly using NEBuilder HiFi DNA Assembly Master Mix (NEB).

DHCR24 specific shRNA sequences were selected by BLOCK-iTTM RNAi Designer (http://rnaidesigner.thermofisher.com/rnaiexpress/). The shRNA sequences were as follows: shRNA-6 (5'CCGCGTGTGAAACACTTTGA-3'), shRNA-7 (5'-GCTCTCGCTTATCTTCGATA-3'), and control shRNA (shNC) (5'-GGTACGGTCAGGCAGCTTCT-3'). Short-hairpin sequences were synthesized as oligonucleotides and annealed according to standard protocol. Annealed shRNAs were then subcloned into pLL3.7 shRNA vectors (Addgene).

\section{Establishment of stable melanoma cell lines}


The lentivirus was packaged into the helper plasmids (PSPAX2, PMD2.G) by cotransfection of 293T cells. The supernatant of the 293T cells packages lentivirus was harvested. A375 and A2058 cells were transduced with the lentivirus and $8 \mu \mathrm{g} / \mathrm{ml}$ polybrene. Stable transfected cells were incubated at $37^{\circ} \mathrm{C}$ with $5 \% \mathrm{CO}_{2}$ for $48 \mathrm{~h}$, then selected by $1 \mu \mathrm{g} / \mathrm{ml}$ puromycin for one-two weeks and maintained with 0.8 $\mathrm{mg} / \mathrm{ml}$ puromycin.

\section{Subcutaneous tumor formation}

Six- to eight-week-old BALB/c-nu/nu female mice were purchased from Biotechnology Co., Ltd. (Beijing, China) and fed under SPF conditions in Institute of Radiation Medicine, Chinese Academy of Medical Science \& Peking Union Medical College (Tianjin, China). All animal experiments were approved by the Institution's Ethics Committee.

Mice were injected subcutaneously with $1 \times 10^{7}$ cells $(0.1 \mathrm{ml} \mathrm{PBS})$ and weighed twice a week. The volume of tumor was measured after three weeks and calculated by the equation (length ' width ${ }^{2} / 2$ ). Tumors were fixed in $4 \%$ paraformaldehyde for hematoxylin-eosin (HE) staining.

\section{Real-Time quantitative PCR analyses}

Total RNA was prepared from cells using EasyPure® RNA Kit (TransGen Biotech.) and reversely transcribed using TransScript ${ }^{\circledR}$ All-in-One First-Strand cDNA Synthesis SuperMix for qPCR (TransGen Biotech.) according to the manufacturer's protocol. Real-Time quantitative PCR was performed using SYBR SuperMix (TransGen Biotech.) and specific primers for DHCR24 (forward 5'-

GTGAAACACTTTGAAGCCAGG-3', reverse 5'-AGCCATCAAACATCTCCCAG-3') CYP27A1 (forward 5'CATGGAGCTATGGAAGGAGC-3', reverse 5'-TGAAAGCATCCGTATAGAGCG-3'), and GAPDH (forward 5'AGCCACATCGCTCAGACAC-3', reverse 5'-TTAAAAGCAGCCCTGGTGAC-3'). All the samples were normalized to the housekeeping gene, GAPDH. Data were calculated using the $2-\Delta \Delta \mathrm{Ct}$ method.

\section{RNA-seq analyses}

Total RNA was obtained from fresh cells using EasyPure ${ }^{\circledR}$ RNA Kit (TransGen Biotech.) following the manufacturers' protocol. Paired-end read of $100 \mathrm{bp}$ (or $150 \mathrm{bp}$ ) were prepared in a BGISEQ-500 platform. The read number of each gene was converted to Fragments-Per-Kilobase per Million mapped fragments (RPKM) and differentially expressed genes were analyzed by DEseq2 package. Heatmap, GSEA enrichment, GO enrichment and KEGG enrichment were obtained via online Dr.Tom (https://biosys.bgi.com/\#/main).

\section{Western Blot analysis}

Protein lysates from cells were extracted in RIPA buffer, with 1' protease inhibitors cocktail. Equal number of proteins were resolved by $12 \%$ SDS-PAGE gel and transferred onto PVDF membranes. The blots were blocked and incubated with primary antibodies overnight at $4^{\circ} \mathrm{C}$. Then membranes were incubated with the secondary antibody at $37^{\circ} \mathrm{C}$ for $1 \mathrm{~h}$. The blots were probed with anti-DHCR24 (Santa Cruz 
Biotechnology, sc-398938), anti-CYP27A1(Thermo Fisher Scientific, PA5-27946), anti-Rap1 (Santa Cruz Biotechnology, sc-53434), anti-AKT1 (Santa Cruz Biotechnology, sc-5298) and anti-pAKT1-Thr308/309 (Signalway Antibody, 13311). GAPDH (TransGen, HC301) were used as the internal control. Densitometry analysis was performed using ImageJ software.

\section{Cell growth and cell cycle analysis}

Cell proliferation was assesd using TransDetect ${ }^{\circledR}$ Cell Counting Kit (TransGen Biotech.) according to the manufacturer's instructions. Briefly, cells were plated in a 96-well plate at $3 \times 10^{3}$ cells/well and the absorbance value (OD) was measured at $450 \mathrm{~nm}$ using a microplate reader. Cells were fixed with $70 \%$ ethanol at $4^{\circ} \mathrm{C}$ overnight for cell cycle assay. Cells were added RNase $A(100 \mu \mathrm{g} / \mathrm{ml})$ for $5 \mathrm{~min}$ at room temperature, then stained with PI ( $50 \mu \mathrm{g} / \mathrm{ml}$, US EVERBRIGHT) for $30 \mathrm{~min}$ at room temperature. All samples were detected using a flow cytometer (NovoCyte 2040R, Agilent Technologies) and analyzed using the NovoExpress 1.4.1 software (Agilent Technologies).

\section{Wound healing assay}

Cells were seeded in 6-well plates and wounds were generated using a $200-\mu l$ micropipette tip in the middle of each well. The migrated distances were measured at 0 and $48 \mathrm{~h}$ after scratching in the same wounded region using an inverted microscope. The data were processed using Image $\mathrm{J}$ software.

\section{Tumorsphere formation}

To prepare poly-hydroxyethyl methacrylate (poly-HEMA, Sigma) coated plates, $300 \mu \mathrm{l}$ of $12 \mathrm{mg} / \mathrm{ml}$ polyHEMA was added to each well of 12 -well plates and put on the shaker at $37^{\circ} \mathrm{C}$ overnight. Cells $\left(5 \times 10^{3}\right.$ cells/well) were plated in triplicate in poly-HEMA coated 12-well plates using DMEM/F-12 medium (Gibco), supplemented with penicillin $(100 \mathrm{U} / \mathrm{ml}) /$ streptomycin $(100 \mu \mathrm{g} / \mathrm{ml})$ (TransGen Biotech.), Lglutamine (2 mM, Gibco), B27 supplement (1x, Thermo), bFGF ( $20 \mathrm{ng} / \mathrm{ml}, \mathrm{MCE})$, and hEGF $(20 \mathrm{ng} / \mathrm{ml}$, Gibco). Tumorsphere with a diameter greater than $50 \mu \mathrm{m}$ were counted using an inverted microscope.

\section{Determination of cholesterol metabolites}

$1 \times 10^{7}$ cells were collected and added $400 \mu \mathrm{L}$ methanol: water: chloroform (5:2:2, v/v/v) mixed solution. The samples were homogenized in a microhomogenizer for $3 \mathrm{~min}$, and extracted ultrasonically in an icewater bath. The supernatant was collected and concentrated with centrifugal concentration dryer. Dried lipids were dissolved with $200 \mu \mathrm{l}$ methanol: water $(4: 1, \mathrm{v} / \mathrm{v})$ mixture solution and swirled in ice water bath until mixture is homogenous. Then the sample were filtered with $0.22 \mu \mathrm{m}$ organic phase pinhole filter for LC-MS analysis.

Liquid chromatography was performed using an UPLC system (Nexera UHPLC LC-30A). The chromatographic column was the Waters UPLC HSS C18 Column $(2.1 \mathrm{~mm} \times 100 \mathrm{~mm}, 1.7 \mu \mathrm{m})$. The mobile phase $A$ was water containing $0.1 \%$ formic acid, and the mobile phase $\mathrm{B}$ was acetonitrile. The temperature of column was $45^{\circ} \mathrm{C}$, and the flowing rate of mobile phase was $0.4 \mathrm{ml} / \mathrm{min}$. Gradient 
conditions were as follows: 0-0.5 min, 40\% B, 0.5-1 min, 40\%-55\% B, 1-8 min, 50\%-90\% B, 8-9.2 min, 90\%-40\% B, 9.2-10 min, 40\% B. Mass spectrometry analyzed using an AB Sciex Qtrap 5500 system containing an electrospray ionization (ESI) source. The capillary voltage was set to 5500V for positive mode and $4500 \mathrm{~V}$ for negative mode. The mass spectra were acquired in a mass range of $\mathrm{m} / \mathrm{z} 100-$ 1000, and collision-activated dissociation (CAD) was medium. Other parameters were as follow: ion source gas 1, 60 psi, ion source gas 2, 50 psi, curtain gas (CUR), 35 psi, and turbo ion spray source temperature, $500{ }^{\circ} \mathrm{C}$.

All standards were purchased from Sigma and prepared at the concentrations of $0.05 \mathrm{ng} / \mathrm{ml}, 0.13 \mathrm{ng} / \mathrm{ml}$, $0.33 \mathrm{ng} / \mathrm{ml}, 0.82 \mathrm{ng} / \mathrm{ml}, 2.05 \mathrm{ng} / \mathrm{ml}, 5.12 \mathrm{ng} / \mathrm{ml}, 12.80 \mathrm{ng} / \mathrm{ml}, 32.00 \mathrm{ng} / \mathrm{ml}, 80.00 \mathrm{ng} / \mathrm{ml}, 200.00 \mathrm{ng} / \mathrm{ml}$, $500.00 \mathrm{ng} / \mathrm{ml}$ and $1000.00 \mathrm{ng} / \mathrm{ml}$. The content of cholesterol and its metabolites in different cells were obtained according to standards.

\section{Tissue Microarrays (TMAs) and Immunohistochemistry (IHC)}

Skin cancer tissue Microarray (K063Me01) was purchased from Xi'an bioaitech Co., Ltd (Xi'an, China). The samples were analyzed by IHC using an anti-DHCR24 antibody according to standard method and microarray instruction. The results were randomly observed 5-10 fields of view, and then taken the average.

\section{Measurement of $27-H C$}

Human 27-HC ELISA Kit was obtained from Wuhan Fine Biotech Co., Ltd (Wuhan, China). Cells (2x106) were collected and detected for 27-HC content following the manufacturer's protocol. The OD value was measured by a Microplate Reader (Thermo) at $450 \mathrm{~nm}$. The concentration of cellular 27-HC was obtained according to standards.

\section{Statistical analysis}

The GraphPad Prism v8.0 software was used to perform all statistical analyzes. Student's t-test was performed to compare two groups, a one-way ANOVA was performed to compare more than two groups. All experiments were repeated at least three times. Data were represented as the mean \pm SEM. $P$ value $<$ 0.05 was considered statistically significant.

\section{Results}

Highly expression of DHCR24 in melanoma patients and DHCR24 increases tumor growth in xenograft mice

To investigate the role of DHCR24 in melanoma patients, Hematoxylin-Eosin (HE) staining and immunohistochemical (IHC) staining via tissue chip were performed, containing normal skin tissue $(n=15)$, malignant melanoma $(n=38)$ and metastatic malignant $(n=10)$ melanoma patient samples (details were provided in Supp Table 1). The results demonstrated that the expression of DHCR24 was 
significantly higher in malignant melanoma, especially in metastatic malignant melanoma, compared with control (Fig. 1 A).

Next, in order to illustrate the effect of DHCR24 on tumorigenic ability in nude mice, xenograft mice assay was performed using DHCR24 overexpression and control melanoma cells. After 21 days, the tumor volume increased significantly in DHCR24 group, while there was no significant change in body weight (Fig. 1 B-D). HE staining showed that the tumor cells in DHCR24 and control group were disordered, the polarity disappereaed, nuclear atypia and intercellular vascular congestion (Fig. 1 C). However, there were mitotic figures in the DHCR24 group, which indicates that malignancy was more severed in the DHCR24 group than that in the control group. These data indicated that DHCR24 maybe act as a novel oncogene in melanoma cells.

\section{DHCR24 is essential to melanoma survival and migration}

To validate the oncogenic function of DHCR24, we performed shRNA-based DHCR24 knockdown in melanoma cells. Using two different shRNA constructs to knock down DHCR24, we observed that the knockdown efficiency of sh6 and sh7 was more significant (Fig. 2 A-B). DHCR24 knockdown significantly slowed down cell proliferation at 48-96 h compared with control (Fig. $2 \mathrm{C}$ ). Flow cytometry analysis showed that the DHCR24 silencing significantly reduced cell numbers in the $\mathrm{G} 1$ phase while increased cell numbers in S phase (Fig. 2 D), which may inhibit cell proliferation and induce cell apoptosis. Moreover, wound healing assay revealed that the migration rate of melanoma cells with DHCR24 knockdown was lower compared with control (vector as a control) (Fig. $2 \mathrm{E}$ ). Taken together, these results suggested that DHCR24 played a critical role in melanoma cell survival and migration.

\section{DHCR24 promotes the formation of melanoma stem-like cells by Rap1 signaling}

To evaluate the effect of the DHCR24 on melanoma stem-like cells, the tumorsphere formation analysis was performed in the stable DHCR24 expressed melanoma cells. After 7-10 days culture, the well annotated stemness markers, Stat3 and KIf4 in tumorsphere, were strongly increased compared to their levels in adherent cells (Supp Figure 1). Besides, we found that the numbers and size of DHCR24 expressed tumorspheres were significantly increased in melanoma cells, confirming that DHCR24 could promote the proliferation of melanoma stem-like cell populations in melanoma cells (Fig. 3 A).

To decipher the molecular mechanism underlying DHCR24, whole transcriptome sequencing was performed on melanoma stem-like cells expressing DHCR24 and control (vector as control). The heatmap showed that 134 differentially expressed genes, including 38 downregulated genes and 96 upregulated genes (genes with a fold change $\geq 2$ and a P-value (t-test) $<0.05$ were collected) (Fig. 3 B). The KEGG pathway enrichment analysis of 96 upregulated genes demonstrated that Rap1 signaling pathway which is the upstream of PI3K/AKT signaling pathway was significantly enhanced in melanoma stem-like cells (Fig. 3 C). We next determined the expression changes of Rap1 and pAKT (thr 308/309) protein by western blot. The results showed that Rap1 and pAKT (thr 308/309) were significantly increased in mammosphere melanoma cells with stable DHCR24 expressed (Fig. 3 D). Taken together, these data 
revealed that DHCR24 promoted the formation of melanoma stem-like cell populations via activating AKT signaling pathway.

\section{DHCR24 induced cellular 27-HC accumulation in melanoma cells}

Among the rate-limiting enzymes in cholesterol metabolism, DHCR24 is the final enzyme of the cholesterol biosynthetic pathway that converts desmosterol into cholesterol by catalyzing the reduction of the $\mathrm{C} 24=\mathrm{C} 25$ unsaturation in the side-chain (Fig. $4 \mathrm{~A}$ ). And considering that cholesterol is an essential lipid to maintain cell homeostasis and provide energy for cancer cell rapid proliferation [41], we ought to ask whether cholesterol contributes to the proliferation of melanoma stem-like cell populations. Thus, we treated the A375 and A2058 melanoma cells with different concentrations $(0,5 \mu \mathrm{M}, 10 \mu \mathrm{M}, 50 \mu \mathrm{M})$ of cholesterol on the poly-HEMA coated 12-well plates under the condition of tumorsphere formation for 710 days. As shown in Fig. 4 B, the numbers and size of tumorspheres increased significantly in melanoma cells with the addition of exogenous $50 \mu \mathrm{M}$ cholesterol compared with ethanol control group. The results showed that cholesterol significantly promotes the growth of melanoma stem-like cells in melanoma cells.

We next investigate the variation of cholesterol metabolites profiles driven by DHCR24. Cellular cholesterol and its metabolites in A2058 with stable expressing DHCR24 was characterized by LC-MS, and 8 of 17 metabolites, including cholesterol, were quantified. Beyond our expectation, only 27-HC levels were increased by $41.39 \%$ with statistical significance $(n=6, p=0.0000751)$, but there was no significant change in the cellular cholesterol contents $(n=6, p=0.0951267)$ (Supp Table 2 and Fig. 4 C). These results were coincided with recently reported that $27-\mathrm{HC}$ promotes breast cancer cell proliferation, invasion, and migration [22-24] and CYP27A1, coding 27-hydroxylase that catalyze cholesterol into 27-HC, was highly expression in melanoma patients and cell lines compared with nomal paitients and melanocytes (Fig. $4 \mathrm{D}$ and Supp Figure 2. Moreover, we found that DHCR24 could induced the expression of CYP27A1 in the metastasis melanoma cell A2058 (Fig. 4 E). These results indicated that there might be a potential positive feedback mechanism for amplifying CYP27A1 expression in melanoma and increased 27-HC content eventually.

\section{7-HC promotes the proliferation of melanoma stem-like cell populations}

To validate the role of 27-HC on melanoma stem-like cells induced by DHCR24, we established stable melanoma cell lines with expressed CYP27A1 and then evaluated the changes of 27-HC contents compared with empty vector control (Fig. 5 A). Without DHCR24 induction, we observed that CYP27A1 alone triggered the cellular accumulation of $27-\mathrm{HC}$ and promoted the proliferation of melanoma stem-like cell populations both in A375 and A2058 melanoma cells (Fig. 5 B-C). Correspondingly, tumorsphere formation assay in wild type melanoma cells treated with different concentrations $(0,1 \mathrm{nM}, 5 \mathrm{nM}, 50 \mathrm{nM}$ and $100 \mathrm{nM}$ ) of $27-\mathrm{HC}$ was performed as well. As shown in Fig. $5 \mathrm{D}$, when treated with 27-HC for 7-10 days, the numbers and size of tumorspheres were significantly increased in A375 and A2058 melanoma cells with administration of exogenous $100 \mathrm{nM} 27-\mathrm{HC}$ compared with control (ethanol as control). These 
data validated that $27-\mathrm{HC}$ promoted melanoma stem-like cell proliferation as downstream effector of DHCR24.

\section{DHCR24 contributes to vemurafenib resistance by activating AKT pathway}

Previously research has shown that CSCs contribute to resist radiation, chemotherapy and drug resistance in cancer therapy [42]. However, the linking between metabolic abnormality of cholesterol and CSCs is still not well elucidated. According to the data in Fig. 3-4, DHCR24 increased the proliferation of melanoma stem-like cell by inducing the expression of CYP27A1 and subsequently cellular accumulation of 27-HC. Thus, we hypothesized that DHCR24 and its downstream metabolite 27-HC may contribute to drug resistance in targeted therapy of advanced melanoma. To confirm that, 27-HC administrated, DHCR24 and CYP27A1 expressing stable melanoma cell lines were treated using multiple concentrations $(0,1,5,10$ and $20 \mu \mathrm{M})$ of BRAFV600E inhibitor vemurafenib for 2 days (DMSO as control), respectively. Cell proliferation assay results showed that $27-\mathrm{HC}$ administration, the expression of DHCR24 and CYP27A1 significantly reduced the sensitivity for vemurafenib induced proliferation inhibition. (Fig. 6 AB and Supp Figure 3).

We have previously demonstrated that DHCR24 promotes the formation of melanoma stem-like cells by Rap1/AKT signaling pathway and the activation of PI3K/AKT signaling pathway has been proved to be associated with obtained resistance in many types of cancer $[43,44]$. Therefore, we next determined the activities of AKT signaling in DHCR24 expressing melanoma cells treated with BRAFV600E inhibitor, vemurafenib, in $1 \mathrm{uM}$ and $5 \mathrm{uM}$ conditions. When DHCR24 expressing A375 and A2058 melanoma cell lines were exposure to vemurafenib, we observed that the phosphorylation of AKT (pAKT) at thr308/309 sites were strongly enhanced (Fig. 6 C). Thus, we concluded that DHCR24 caused the drug resistance of vemurafenib by reactivating AKT signaling in melanoma cells. Finally, we drew a schematic diagram to summarize our findings in present investigation that DHCR24 promotes melanoma stem-like cells formation and mediates vemurafenib resistance by accumulating $27-\mathrm{HC}$ and reactivating AKT signaling (Fig. 6 D).

\section{Discussion}

Cholesterol is the precursor of steroid hormones and bile acids and essential component of cell membranes. Despite the controversy of statin use and cancer risk, there is increased cholesterol biosynthesis in cancers thereby implicating its potential role in tumorigenesis and cancer metastasis [4446]. Targeting cholesterol metabolism is presently being utilized as a potential therapeutic approach to cancer therapy. It is reported that targeting SQLE and HMGCR to inhibit cholesterol biosynthesis can slow down the cell growth and induce apoptosis in breast and prostate cancers [47]. While hypercholesterolemia is shown to promote mammary tumor growth and invasiveness in several mouse transgenic models [48-50]. It is worth noting that in cancer cells, cholesterol maybe not the ultimate effector for cancer survival. The intermediate metabolites of cholesterol have been demonstrated various functions in tumorigenesis. We and others previously showed that 7-dehydrocholesterol and vitamin K3 
inhibited melanoma cell proliferation and induce apoptosis via AKT/MAPK signaling pathways [5153]. while Nelson et al. found that cholesterol metabolite 27-HC, as a partial agonist for the estrogen receptor and the liver $\mathrm{X}$ receptor, promoted tumor growth and metastasis in mouse models of mammary cancer [24]. Indeed, our data showed that force expression of DHCR24 increase the cellular 27-HC contents without affecting cholesterol contents in melanoma cells. Meanwhile, it was found that level of the enzyme expressing cholesterol to 27-HC (CYP27A1) in melanoma cells and human malignancy melanoma was significantly increased, suggesting that $27-\mathrm{HC}$ produced within tumors may contribute to tumorigenesis. Further administration of 27-HC in melanoma cell validated that DHCR24 promotes the proliferation of melanoma stem-like cell populations by accumulating 27-HC content in melanoma cells. Meantime, we found that the DHCR24 could induced the expression of CYP27A1 in metastatic malignant melanoma A2058 cells but not in primary melanoma A375 cells. The result was consistent with the phenotypes which forced overexpression of DHCR24 or CYP27A1 showed stronger resistance to vemurafenib in metastatic melanoma A2058 cells, however, the mechanism underlying needs to be further explored.

Cancer stem cells (CSCs) are considered to be the main causes that result in the clinical outcome of poor prognosis due to the "stemness" of tumorigenesis[54-56]. Increased cholesterol biosynthesis lead to breast CSCs propagation and impaired outcome of patients [26]. Consistent with that, we found that cholesterol could promote the growth of melanoma stem-like cell populations in melanoma cells. We next ask which limiting enzyme contribute to cholesterol deregulation in melanoma and which patients could specifically benefit from it as a biomarker or therapeutic target. DHCR24 is the final step enzyme that catalyzes desmosterol into cholesterol. It participates in a variety of cellular functions, such as oxidative stress, cell differentiation, anti-apoptotic function, anti-inflammatory activity. Dysregulation of DHCR24 is implicated in Alzheimer's disease and cancers [57] and the knockout mice demonstrate lethal dermopathy with differentiation and maturation defects in the epidermis [58]. In present study, our patient derived sample results illustrated that DHCR24 was upregulated in malignant melanoma compared with normal skin tissues, which was consistent with the previous conclusions that DHCR24 expression was increased in metastatic melanoma and high DHCR24 levels are associated with stronger growth ability of tumor cells [39]. The latest study also found that the up-regulated expression of DHCR24 in endometrial carcinoma was significantly correlated with advanced clinical stage, histological grade, vascular invasion, lymphatic metastasis and reduced overall survival [59]. Therefore, DHCR24 may play a role as a tumor promoting factor in melanoma, which can predict the clinical prognosis of melanoma patients. We observed that forced expression of DHCR24 promotes the growth of tumor in xenograft mice while knockdown of DHCR24 blocks cells in S phase and results in significant inhibition of cell proliferation and migration in melanoma cells. Importantly, DHCR24 reproduced cholesterol phenotype in promoting melanoma stem-like cells formation as well, indicating the oncogenic role of DHCR24 in melanoma cells.

BRAFV600E mutation is found about $50 \%$ in melanoma patients. However, the long-term survival rate of melanoma patients is still unideal due to resistance to BRAFV600E inhibitor. CSCs were considered to be associated with drug resistance and inherited most drug resistance mechanisms [11]. Moreover, it has been reported that $27-\mathrm{HC}$ promotes cisplatin drug resistance in glioblastoma cells and high 27-HC 
concentration is associated with poor patient outcome [60]. Thus, we subsequently investigate the effect of DHCR24 in BRAFV600E inhibitor resistant. Both of DHCR24 and 27-HC rescued melanoma cell proliferation inhibition induced by vemurafenib treatment. Consistent with our RNA-seq data in melanoma CSCs, vemurafenib resistant induced by DHCR24 was mediated by AKT activation.

\section{Conclusions}

In summary, our results suggest that DHCR24 contributes to drug resistance to melanoma cells and increases the growth of melanoma stem-like cell populations through its biosynthesis of cholesterol metabolite $27-H C$, which may result in poor prognosis of patients. Thus, up-regulation of DHCR24 expression may lead to reduce the long-term survival rate of melanoma patients and DHCR24 could be used as a potential drug target for improving the prognosis rate of melanoma patients.

\section{Abbreviations}

DHCR24, 3 beta-Hydroxysterol Delta (24)-reductase, 27-HC, 27-Hydroxycholesterol, CYP27A1, 27hydroxylase, CSCs, Cancer stem cells, FBS, Fetal bovine serum, DMEM, Dulbecco's Modified Eagle's Medium, PBS, Phosphate-buffered saline, EGF, Epidermal growth factor, bFGF, Basic fibroblast growth factor, TMAs, Tissue Microarrays, IHC, Immunohistochemistry, HE, Hemoxylin and eosin, GO, Gene Ontology, KEGG, Kyoto Encyclopedia of Genes and Genomes, pAKT, phosphorylation AKT, Rap1, Rasproximate-1.

\section{Declarations}

\section{Authors' contributions}

L.B. and C.T.T. conceived and supervised the study. L.B. and Z.F.L designed experiments. Z.F.L. and L.J. performed experiments. L.B., Z.F.L., C.T.T., W.Y., and Y.M.D. analyzed data. L.B., and Z.F.L wrote the manuscript. All authors read and approved the final version of manuscript.

\section{Ethics approval and consent to participate:}

The study was approved by the Ethics Review Committee of Institute of Radiation Medicine, Chinese Academy of Medical Science \& Peking Union Medical College (Tianjin, China) and Tongxu First Hospital (Henan, China).

\section{Funding}

This work was supported by the National Natural Science Foundation of China (Grant No. 31861143017 , 81700153) and Natural Science Foundation of Tianjin city (Grant No. 18JCQNJC13300) 
No potential conflicts of interest are disclosed.

\section{Author details}

${ }^{1}$ Frontiers Science Center for Synthetic Biology and Key Laboratory of Systems Bioengineering (Ministry of Education), School of Chemical Engineering and Technology, Tianjin University, 300072 Tianjin, China.

${ }^{2}$ Collaborative Innovation Center of Chemical Science and Engineering (Tianjin), Tianjin University, 300072 Tianjin, China. ${ }^{3}$ School of Basic Medicine, Guangdong Medical University, Dongguan 523808, Guangdong Province, China. 4Life Science of Institute, Jinzhou Medical University, 121001 Jinzhou, Liaoning Province, China.

\section{Availability of data and materials}

This manuscript includes all data generated and analyzed in this study. More information is available from the corresponding author on request.

\section{References}

1. Siegel RL, Miller KD, Fuchs HE, Jemal A. Cancer Statistics, 2021. CA Cancer J Clin. 2021, 71: 7-33.

2. Society AC. Cancer Facts \& Figures. 2021.

3. Flaherty KT. Narrative review: BRAF opens the door for therapeutic advances in melanoma. Ann Intern Med. 2010, 153: 587-591.

4. Brose MS, Volpe P, Feldman M, Kumar M, Rishi I, Gerrero R et al. BRAF and RAS mutations in human lung cancer and melanoma. Cancer Res. 2002, 62: 6997-7000.

5. Ribas A, Gonzalez R, Pavlick A, Hamid O, Gajewski TF, Daud A et al. Combination of vemurafenib and cobimetinib in patients with advanced BRAFV600-mutated melanoma: a phase 1b study. Lancet oncol. 2014, 15: 954-965.

6. McArthur GA, Chapman PB, Robert C, Larkin J, Haanen JB, Dummer R et al. Safety and efficacy of vemurafenib in BRAF V600E and BRAF V600K mutation-positive melanoma (BRIM-3): extended follow-up of a phase 3, randomised, open-label study. Lancet oncol. 2014, 15: 323-332.

7. Hauschild A, Grob J-J, Demidov LV, Jouary T, Gutzmer R, Millward M et al. Dabrafenib in BRAFmutated metastatic melanoma: a multicentre, open-label, phase 3 randomised controlled trial. Lancet. 2012, 380: 358-365.

8. Flaherty KT, Infante JR, Daud A, Gonzalez R, Kefford RF, Sosman J et al. Combined BRAF and MEK inhibition in melanoma with BRAF V600 mutations. N Engl J Med. 2012, 367: 1694-1703.

9. Al-Hajj M, Wicha MS, Benito-Hernandez A, Morrison SJ, Clarke MF. Prospective identification of tumorigenic breast cancer cells. Proc Nat Acad Sci. 2003, 100: 3983-3988.

10. Prieto-Vila M, Takahashi R-u, Usuba W, Kohama I, Ochiya T. Drug resistance driven by cancer stem cells and their niche. Int J Mol Sci. 2017, 18: 2574. 
11. Najafı M, Mortezaee K, Majidpoor J. Cancer stem cell (CSC) resistance drivers. Life Sci. 2019, 234: 116781.

12. Kuzu OF, Noory MA, Robertson GP. The role of cholesterol in cancer. Cancer Res 2016, 76: 2063-2070.

13. Hutchinson J, Marignol L. Clinical potential of statins in prostate cancer radiation therapy. Anticancer Res. 2017, 37: 5363-5372.

14. Huang BZ, Chang JI, Li E, Xiang AH, Wu BU. Influence of statins and cholesterol on mortality among patients with pancreatic cancer. JNCl: J Natl Cancer Inst. 2017, 109.

15. Ravnskov U, McCully K, Rosch P. The statin-low cholesterol-cancer conundrum. QJM-INT J MED. 2012, 105: 383-388.

16. Matsuzaki M, Kita T, Mabuchi H, Matsuzawa Y, Nakaya N, Oikawa S et al. Large Scale Cohort Study of the Relationship Between Serum Cholesterol Concentration and Coronary Events With Low-Dose Simvastatin Therapy in Japanese Patients With Hypercholesterolemia Primary Prevention Cohort Study of the Japan Lipid Intervention Trial (J-LIT). Circ J. 2002, 66: 1087-1095.

17. Christie CF, Fang D, Hunt EG, Morris ME, Rovini A, Heslop KA et al. Statin-dependent modulation of mitochondrial metabolism in cancer cells is independent of cholesterol content. FASEB J. 2019, 33: 8186-8201.

18. Sorrentino G, Ruggeri N, Specchia V, Cordenonsi M, Mano M, Dupont S et al. Metabolic control of YAP and TAZ by the mevalonate pathway. Nat Cell Biol. 2014, 16: 357-366.

19. Swinnen JV, Brusselmans K, Verhoeven G. Increased lipogenesis in cancer cells: new players, novel targets. Curr Opin Clin Nutr Metab Care. 2006, 9: 358-365.

20. Silvente-Poirot S, Poirot M. Cholesterol and cancer, in the balance. Science. 2014, 343: 1445-1446.

21. Kimbung S, Chang C-y, Bendahl P-O, Dubois L, Thompson JW, McDonnell DP et al. Impact of 27hydroxylase (CYP27A1) and 27-hydroxycholesterol in breast cancer. Endocr Relat Cancer. 2017, 24: 339-349.

22. Baek AE, Yen-Rei AY, He S, Wardell SE, Chang C-Y, Kwon S et al. The cholesterol metabolite 27 hydroxycholesterol facilitates breast cancer metastasis through its actions on immune cells. Nat Commun. 2017, 8: 1-11.

23. Wu Q, Ishikawa T, Sirianni R, Tang H, McDonald JG, Yuhanna IS et al. 27-Hydroxycholesterol promotes cell-autonomous, ER-positive breast cancer growth. Cell Rep. 2013, 5: 637-645.

24. Nelson ER, Wardell SE, Jasper JS, Park S, Suchindran S, Howe MK et al. 27-Hydroxycholesterol links hypercholesterolemia and breast cancer pathophysiology. Science. 2013, 342: 1094-1098.

25. Wang S, Yao Y, Rao C, Zheng G, Chen W. 25-HC decreases the sensitivity of human gastric cancer cells to 5-fluorouracil and promotes cells invasion via the TLR2/NF-KB signaling pathway. Int $J$ Oncol. 2019, 54: 966-980.

26. Ehmsen S, Pedersen MH, Wang G, Terp MG, Arslanagic A, Hood BL et al. Increased cholesterol biosynthesis is a key characteristic of breast cancer stem cells influencing patient outcome. Cell Rep. 2019, 27: 3927-3938. e3926. 
27. Wang C, Li P, Xuan J, Zhu C, Liu J, Shan L et al. Cholesterol enhances colorectal cancer progression via ROS elevation and MAPK signaling pathway activation. Cell Physiol Biochem. 2017, 42: 729-742.

28. Qin Y, Hou Y, Liu S, Zhu P, Wan X, Zhao M et al. A Novel Long Non-Coding RNA Inc030 Maintains Breast Cancer Stem Cell Stemness by Stabilizing SQLE mRNA and Increasing Cholesterol Synthesis. Adv Sci. 2021, 8: 2002232.

29. Wu J, Guo L, Qiu X, Ren Y, Li F, Cui W et al. Genkwadaphnin inhibits growth and invasion in hepatocellular carcinoma by blocking DHCR24-mediated cholesterol biosynthesis and lipid rafts formation. Br J Cancer. 2020, 123: 1673-1685.

30. Brown DN, Caffa I, Cirmena G, Piras D, Garuti A, Gallo M et al. Squalene epoxidase is a bona fide oncogene by amplification with clinical relevance in breast cancer. Sci Rep. 2016, 6: 1-13.

31. Wu C, Miloslavskaya I, Demontis S, Maestro R, Galaktionov K. Regulation of cellular response to oncogenic and oxidative stress by Seladin-1. Nature. 2004, 432: 640.

32. Roux P, Coetzee JF. Tramadol today. Curr Opin Anaesthesiol. 2000, 13: 457-461.

33. Couet J, Sargiacomo M, Lisanti M, et al. Interaction of a Receptor Tyrosine Kinase, EGF-R, EGF-R, with Caveolins: caveolin binding negatively regulates tyrosine and serine/threonine kinase activities. $\mathrm{J}$ Biol Chem. 1997, 272: 30429-30438.

34. Cooper, Michael, K., Porter, Jeffrey, A. et al. Teratagon-mediated inhibition of target tissue response to Shh signaling. Science. 1998, 280: 1603-1603.

35. Crameri A, Biondi E, Kuehnle K, Lütjohann D, Mohajeri MH. The role of seladin-1/DHCR24 in cholesterol biosynthesis, APP processing and A $\beta$ generation in vivo. EMBO J. 2006, 25: 432-443.

36. Battista MC, Guimond MO, Roberge C, Doueik AA, Fazli L, Gleave M et al. Inhibition of DHCR24/Seladin-1 impairs cellular homeostasis in prostate cancer. Prostate. 2010, 70: 921-933.

37. Bonaccorsi L, Luciani P, Nesi G, Mannucci E, Deledda C, Dichiara F et al. Androgen receptor regulation of the seladin-1/DHCR24 gene: altered expression in prostate cancer. Lab Invest. 2008, 88: 10491056.

38. Qiu T, Cao J, Chen W, Wang J, Wang Y, Zhao L et al. 24-Dehydrocholesterol reductase promotes the growth of breast cancer stem-like cells through the Hedgehog pathway. Cancer Sci. 2020, 111: 3653.

39. Di Stasi D, Vallacchi V, Campi V, Ranzani T, Daniotti M, Chiodini E et al. DHCR24 gene expression is upregulated in melanoma metastases and associated to resistance to oxidative stress-induced apoptosis. Int J Cancer. 2005, 115: 224-230.

40. Tian W, Pang W, Ge Y, He X, Wang D, Li X et al. Hepatocyte-generated 27-hydroxycholesterol promotes the growth of melanoma by activation of estrogen receptor alpha. J Cell Biochem. 2018, 119: 29292938.

41. Ikonen E. Cellular cholesterol trafficking and compartmentalization. Nat Rev Mol Cell Biol. 2008, 9: 125-138.

42. Bao S, Wu Q, McLendon RE, Hao Y, Shi Q, Hjelmeland AB et al. Glioma stem cells promote radioresistance by preferential activation of the DNA damage response. Nature. 2006, 444: 756-760. 
43. Burris HA. Overcoming acquired resistance to anticancer therapy: focus on the PI3K/AKT/mTOR pathway. Cancer Chemother Pharmacol. 2013, 71: 829-842.

44. Llaverias G, Danilo C, Mercier I, Daumer K, Capozza F, Williams TM et al. Role of cholesterol in the development and progression of breast cancer. Am J Pathol. 2011, 178: 402-412.

45. Huang B, Song B-I, Xu C. Cholesterol metabolism in cancer: mechanisms and therapeutic opportunities. Nat Metab. 2020, 2: 132-141.

46. Gabitova-Cornell L, Surumbayeva A, Peri S, Franco-Barraza J, Restifo D, Weitz N et al. Cholesterol pathway inhibition induces TGF- $\beta$ signaling to promote basal differentiation in pancreatic cancer. Cancer Cell. 2020, 38: 567-583. e511.

47. Clendening J, Penn L. Targeting tumor cell metabolism with statins. Oncogene. 2012, 31: 4967-4978.

48. Alikhani N, Ferguson RD, Novosyadlyy R, Gallagher EJ, Scheinman EJ, Yakar S et al. Mammary tumor growth and pulmonary metastasis are enhanced in a hyperlipidemic mouse model. Oncogene. 2013, 32: $961-967$.

49. Liu J, Xu A, Lam SL, Wong NS, Chen J. Cholesterol-induced mammary tumorigenesis is enhanced by adiponectin deficiency: role of LDL receptor upregulation. Oncotarget. 2013, 4: 1804-1818.

50. Llaverias G, Danilo C, Mercier I, Daumer K, Capozza F, Williams TM et al. Role of Cholesterol in the Development and Progression of Breast Cancer - ScienceDirect. Am J Pathol. 2011, 178: 402-412.

51. Liu J, Zhong F, Cao L, Zhu R, Qu J, Yang L et al. 7-dehydrocholesterol suppresses melanoma cell proliferation and invasion via Akt1/NF-kB signaling. Oncol Lett. 2020, 20: 1-1.

52. Gelzo M, Granato G, Albano F, Arcucci A, Russo AD, De Vendittis E et al. Evaluation of cytotoxic effects of 7-dehydrocholesterol on melanoma cells. Free Radic Biol Med. 2014, 70: 129-140.

53. Shah M, Stebbins JL, Dewing A, Qi J, Pellecchia M, Ronai ZeA. Inhibition of Siah2 ubiquitin ligase by vitamin K3 (menadione) attenuates hypoxia and MAPK signaling and blocks melanoma tumorigenesis. Pigment Cell Melanoma Res. 2009, 22: 799-808.

54. Saito Y, Kitamura H, Hijikata A, Tomizawa-Murasawa M, Tanaka S, Takagi S et al. Identification of therapeutic targets for quiescent, chemotherapy-resistant human leukemia stem cells. Sci Transl Med. 2010, 2: 17ra19-17ra19.

55. Visvader JE, Lindeman GJ. Cancer stem cells in solid tumours: accumulating evidence and unresolved questions. Nat Rev Cancer. 2008, 8: 755-768.

56. Liu R, Wang X, Chen GY, Dalerba P, Gurney A, Hoey T et al. The prognostic role of a gene signature from tumorigenic breast-cancer cells. N Engl J Med. 2007, 356: 217-226.

57. Wang Y, Rogers PM, Stayrook KR, Su C, Varga G, Shen Q et al. The selective Alzheimer's disease indicator-1 gene (Seladin-1/DHCR24) is a liver X receptor target gene. Mol Pharmacol. 2008, 74: 1716-1721.

58. Mirza R, Hayasaka S, Takagishi Y, Kambe F, Ohmori S, Maki K et al. DHCR24 gene knockout mice demonstrate lethal dermopathy with differentiation and maturation defects in the epidermis. J Invest Dermatol. 2006, 126: 638-647. 
59. Dai M, Zhu X-L, Liu F, Xu Q-Y, Ge Q-L, Jiang S-H et al. Cholesterol synthetase DHCR24 induced by insulin aggravates cancer invasion and progesterone resistance in endometrial carcinoma. Sci Rep. 2017, 7: 1-12.

60. Liu L, Li MY, Xing Y, Wang XY, Wang Y. The oncogenic roles of 27-hydroxycholesterol in glioblastoma. Oncol Lett. 2019, 18: 3623-3629.

\section{Figures}


A

Normal

Malignant

HE

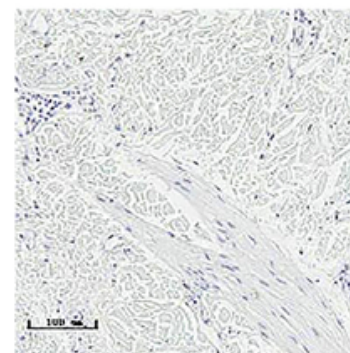

DHCR24
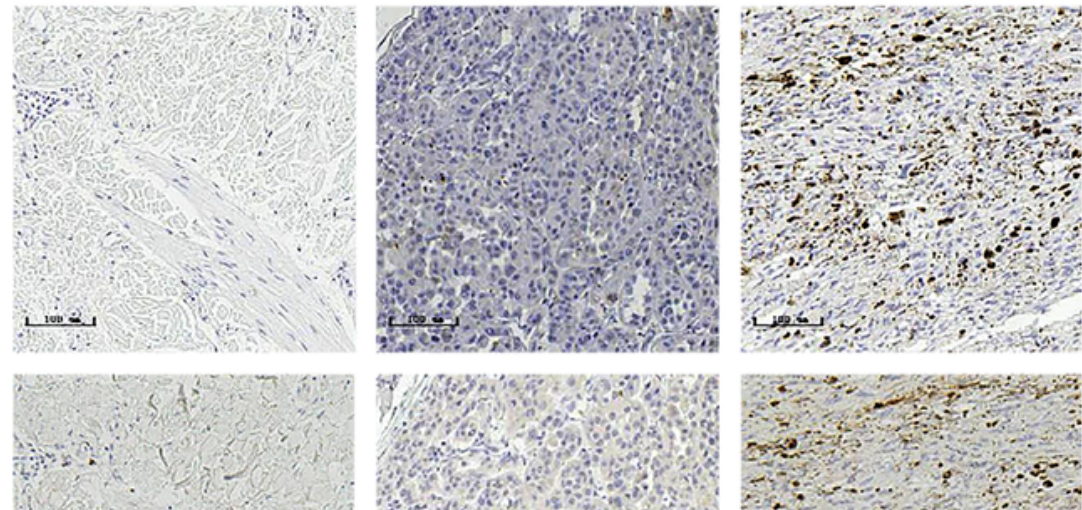

Metastatic
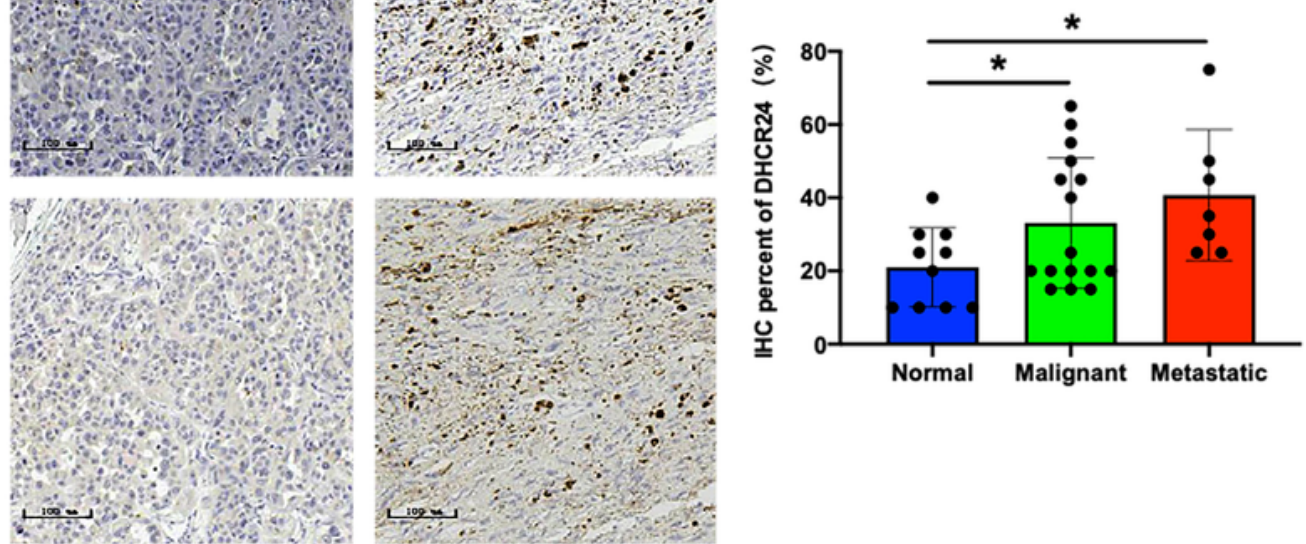

B
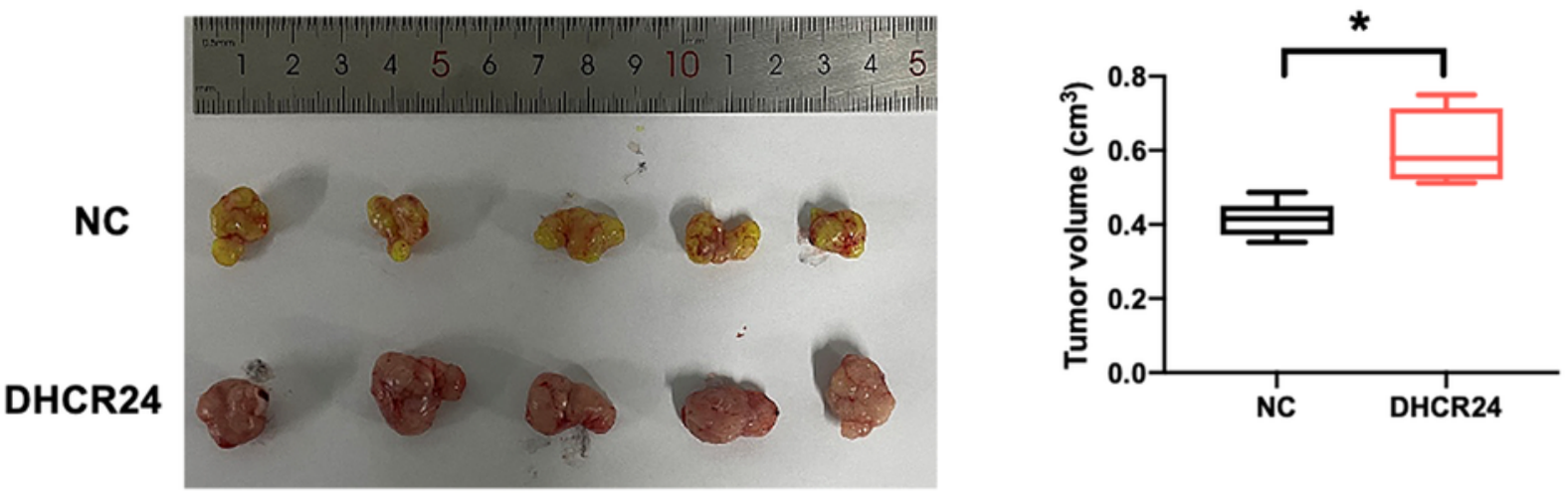

C
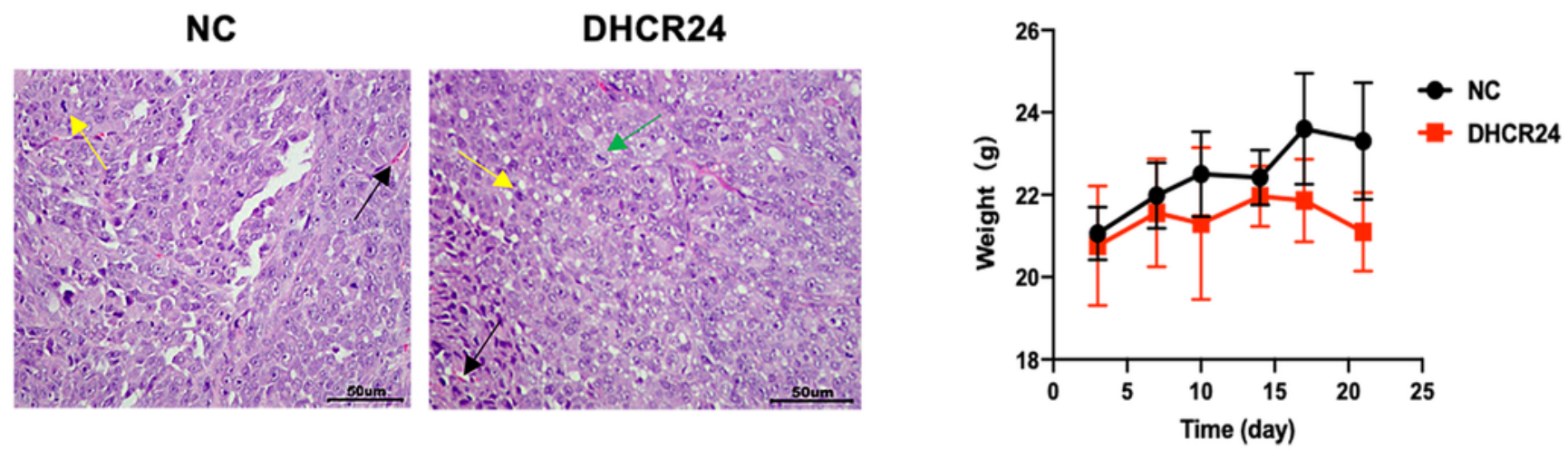

Figure 1

DHCR24 is highly expressed in melanoma patients and increases tumor growth in xenograft mice. (A) Representative images of IHC for DHCR24 in normal skin tissue, malignant melanoma, and metastatic malignant melanoma samples, Negative control groups were examined by conventional hematoxylin and eosin (HE) staining. (B) Subcutaneous tumors generated in BALB/c-nu/nu mice, with DHCR24 transduced A2058 cells. (C) Hematoxylin eosin (HE) tumor staining in transduced A2058 cells. The cells arranged 
disorderly, the polarity disappeared, and the nucleus was heteromorphic (Yellow arrow), Intercellular vascular congestion (Black arrow), Mitotic figure (Green arrow). Magnification $\times 200$. (D) The body weight of mice after $\mathrm{A} 2058$ xenografts. ${ }^{*} P<0.05$.

A
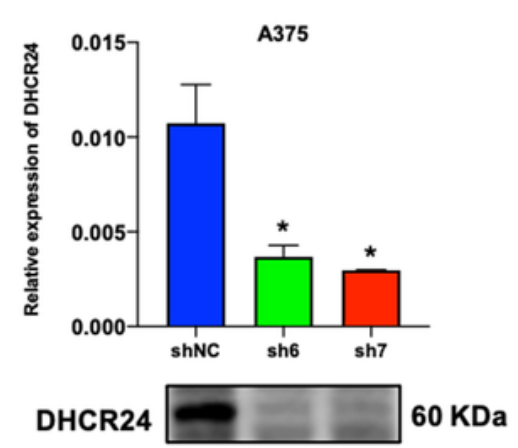

GAPDH

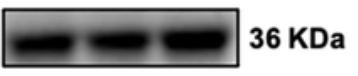

D

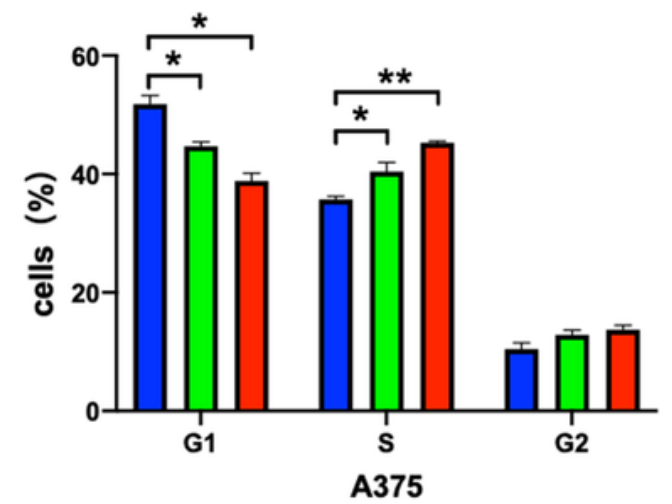

$\mathbf{E}$

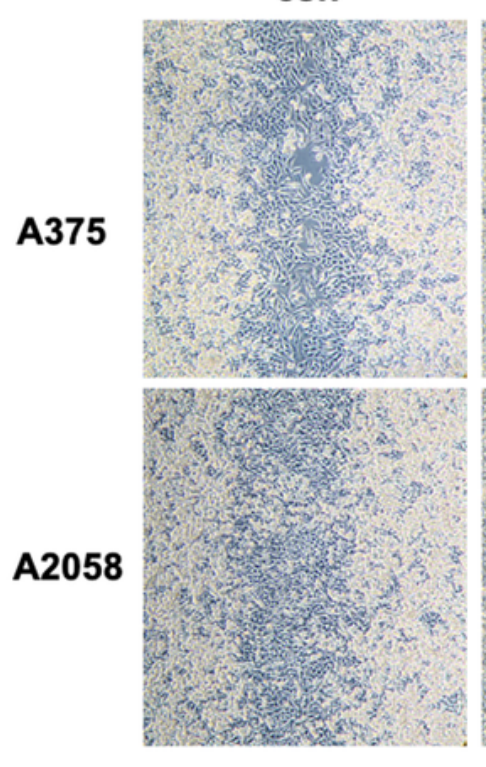

sh6

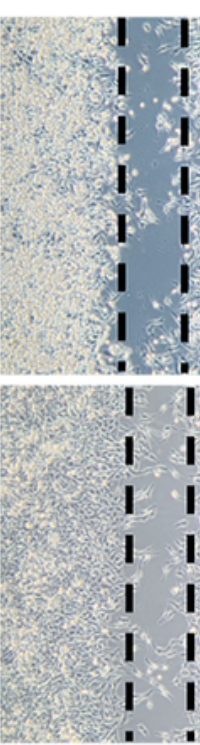

B
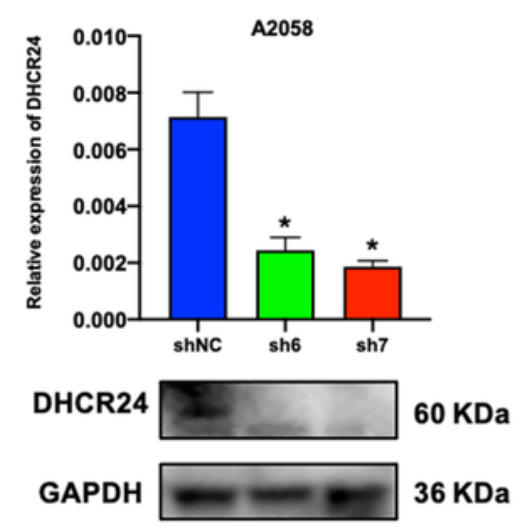

C
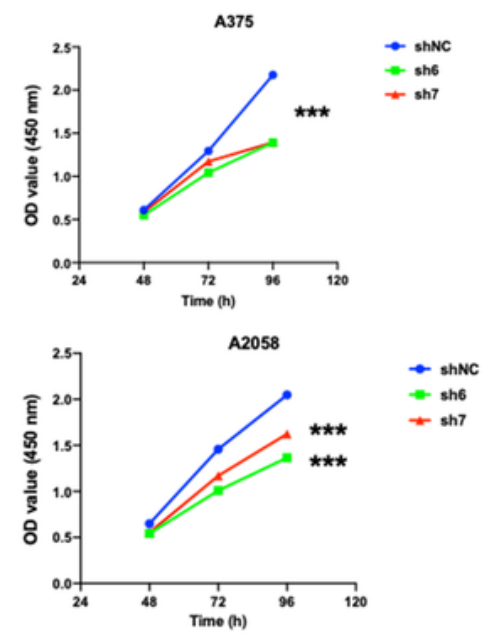
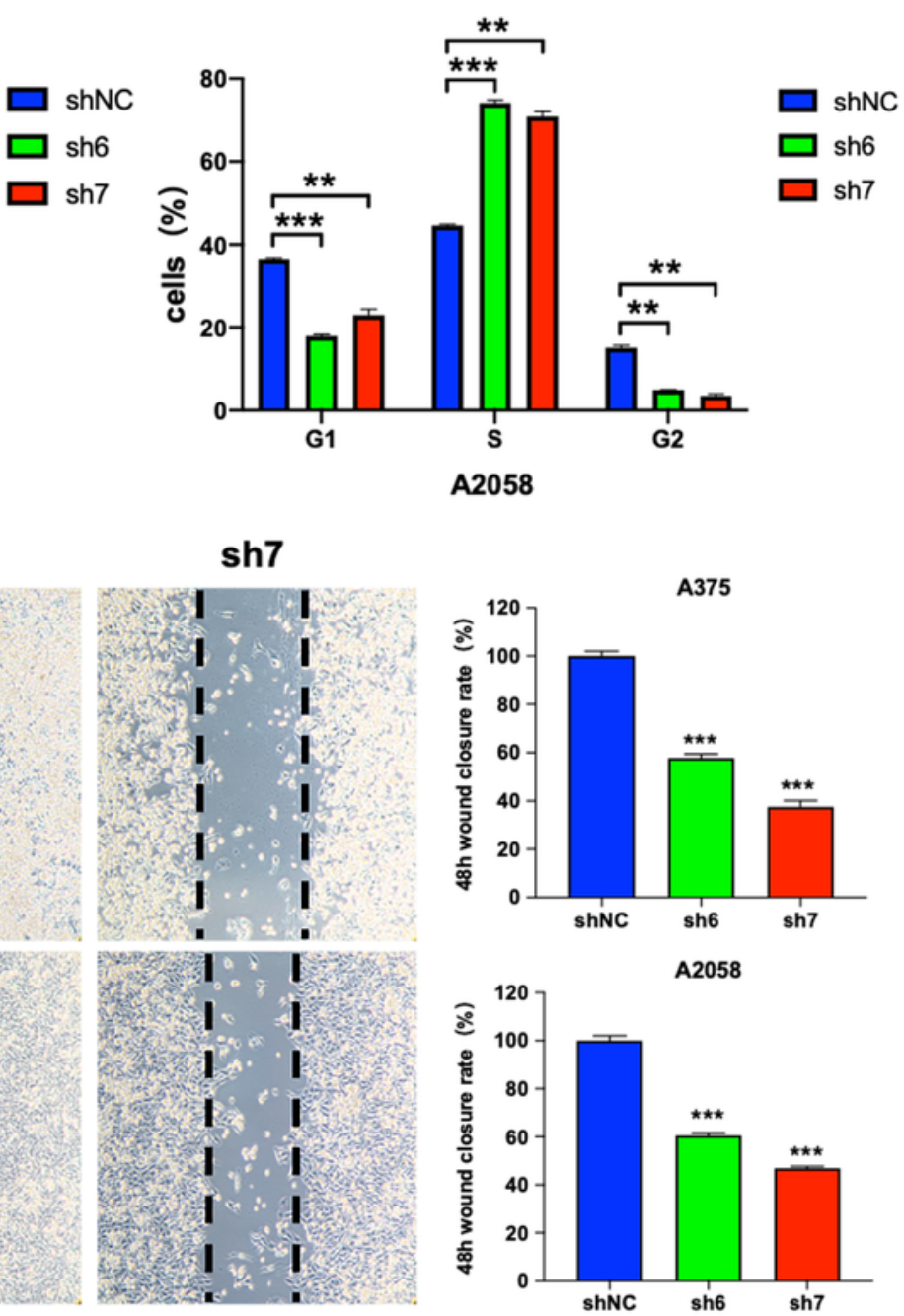

Figure 2 
DHCR24 is essential to cell survival in melanoma cells. (A-B) RT-qPCR and Western blot of DHCR24 in melanoma cell lines A375 and A2058 using pLL3.7 lentivirus expressing negative control shRNA (shNC) and 2 different DHCR24 shRNAs (sh6 and sh7). (C) Proliferation of cells with shNC, sh6 and sh7 targeting DHCR24 at $48 \mathrm{~h}, 72 \mathrm{~h}$ and $96 \mathrm{~h}$. (D) Flow cytometry analysis was performed to assess cell cycle phase status after staining with propidium iodide (PI). (E) Representative statistics of the wound healing assay using cells transfected with the indicated vectors. Magnification $\times 100 .{ }^{\star} P<0.05,{ }^{*} P<0.01,{ }^{\star} * \star P<0.001$. 
A

NC

DHCR24

A375

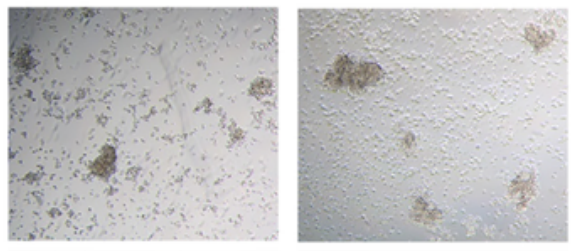

A2058
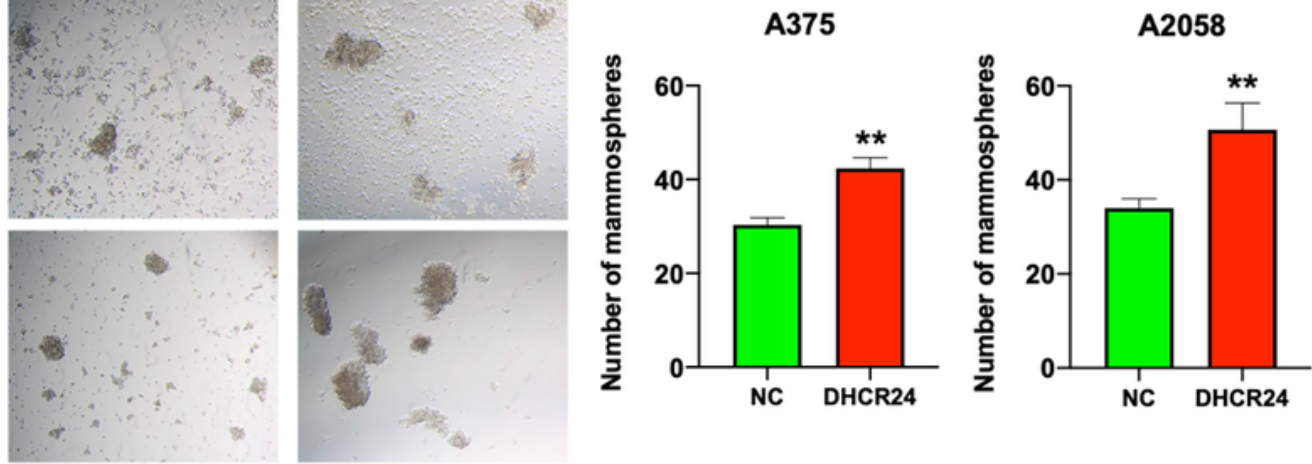

B
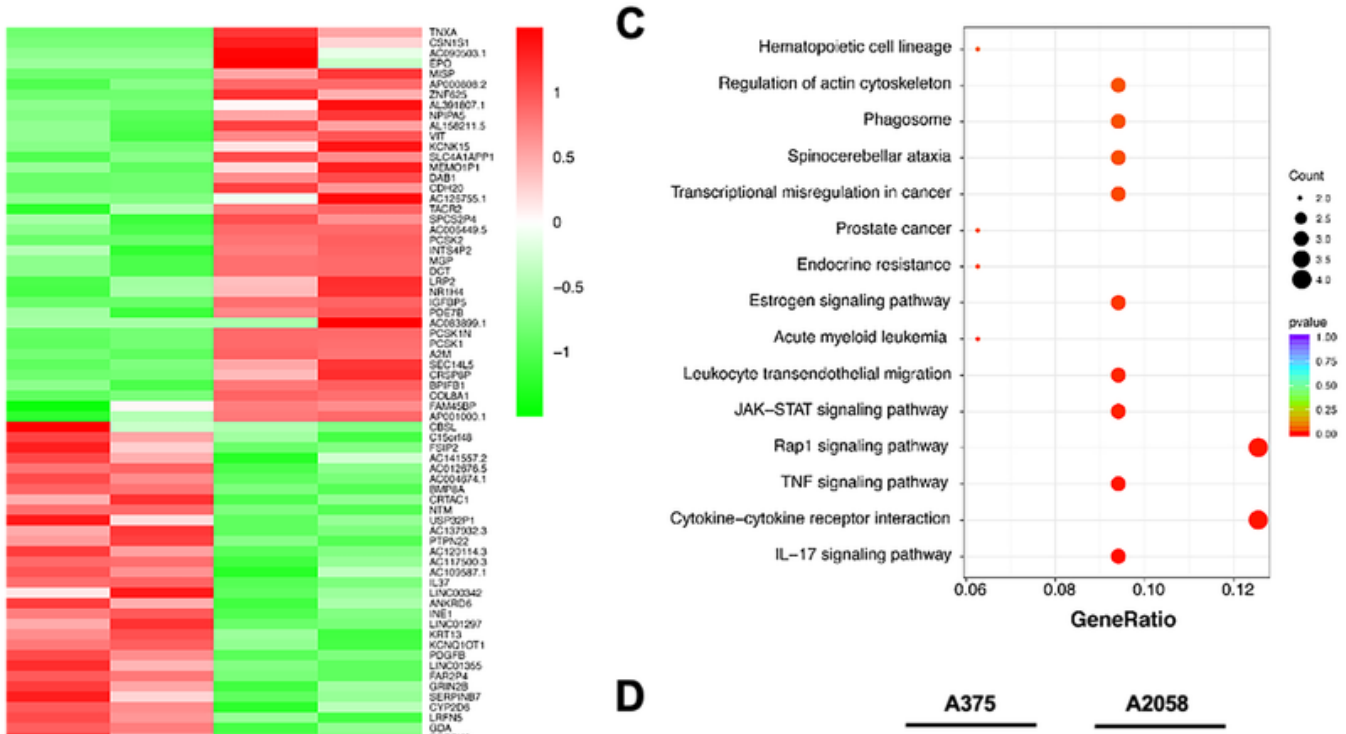

D
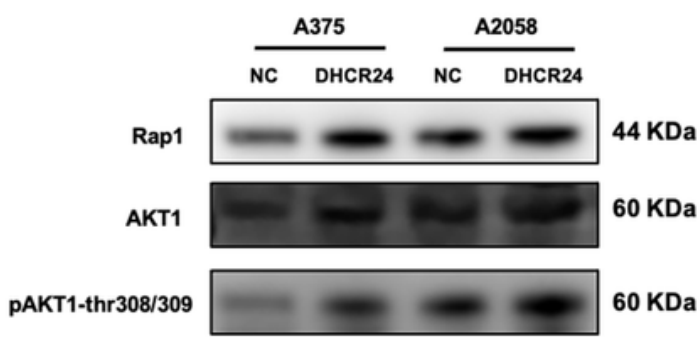

GAPDH
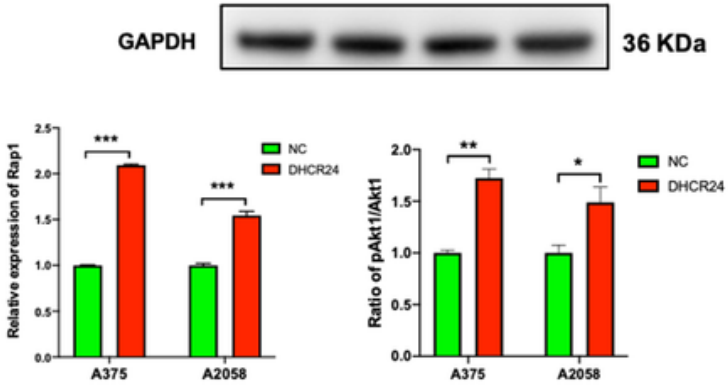

\section{Figure 3}

DHCR24 promotes the formation of melanoma stem-like cells by Rap1 signaling pathway. (A) Tumorsphere formation in A375 and A2058 melanoma cells with overexpressed DHCR24. Cell tumorspheres with diameter $>40 \mu \mathrm{m}$ were counted under $50 \times$ magnification objective lens. (B) The heatmap of A375 stem-like cells with stable DHCR24 overexpression (134 genes, FDR-corrected $P$ value < 0.05 and $\geq 2$-fold change cut-off), 38 genes are relatively downregulated and 96 genes are upregulated. 
(C) The KEGG pathway enrichment analysis (representative pathways) of 96 genes that are upregulated in A375 stem-like cells with stable DHCR24 overexpression. (D) Representative western blots of Rap1, AKT and pAKT in A375 and A2058 melanoma stem-like cells with stable expressed DHCR24. ${ }^{*} P<0.05$, $\star \star P<0.01, * \star \star P<0.001$.

A

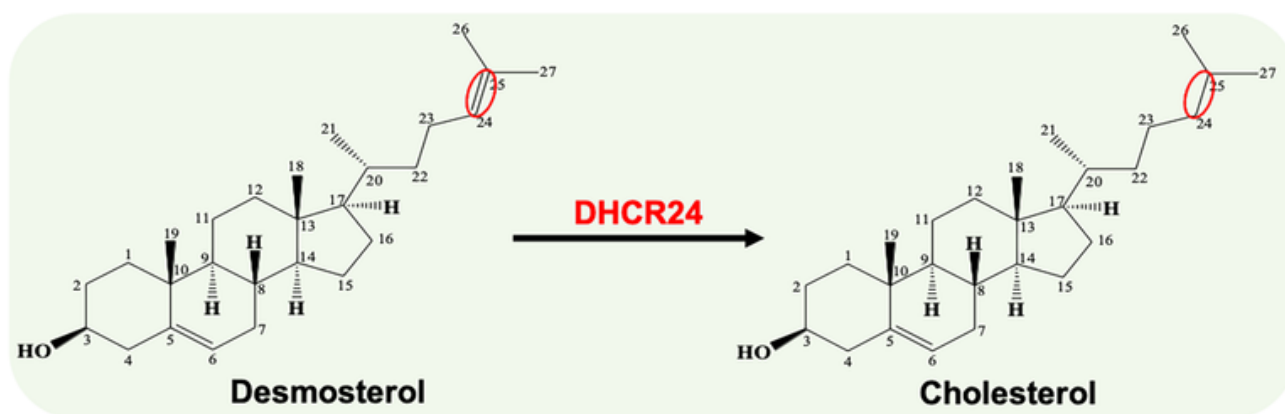

B
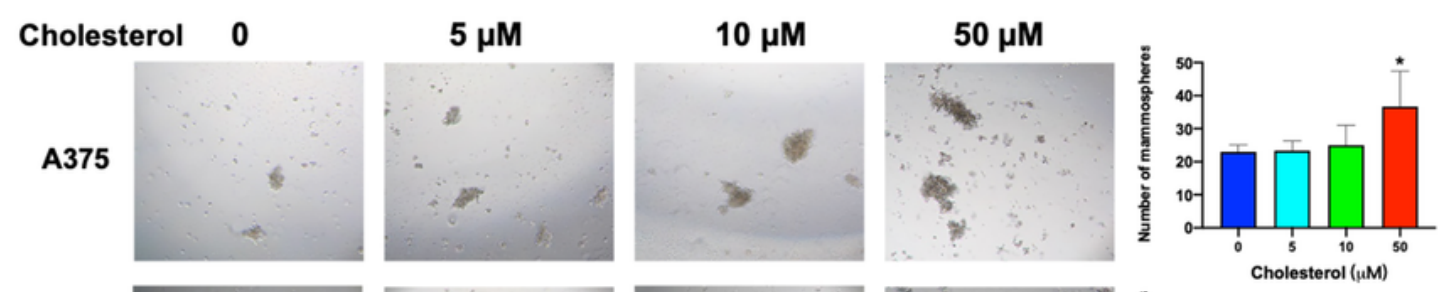

A2058
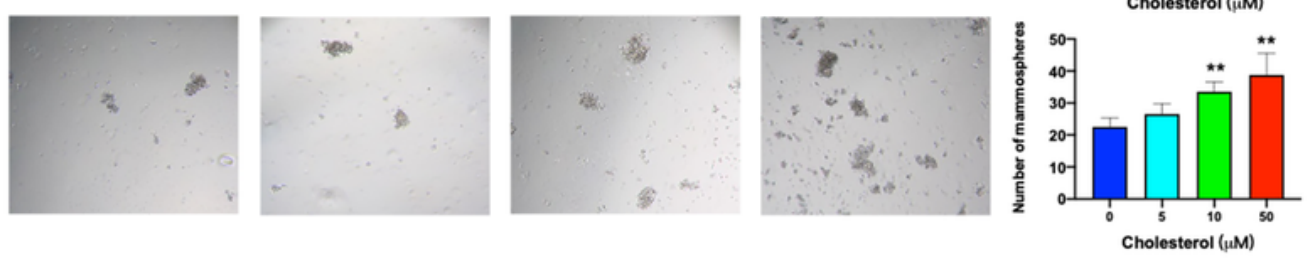

C

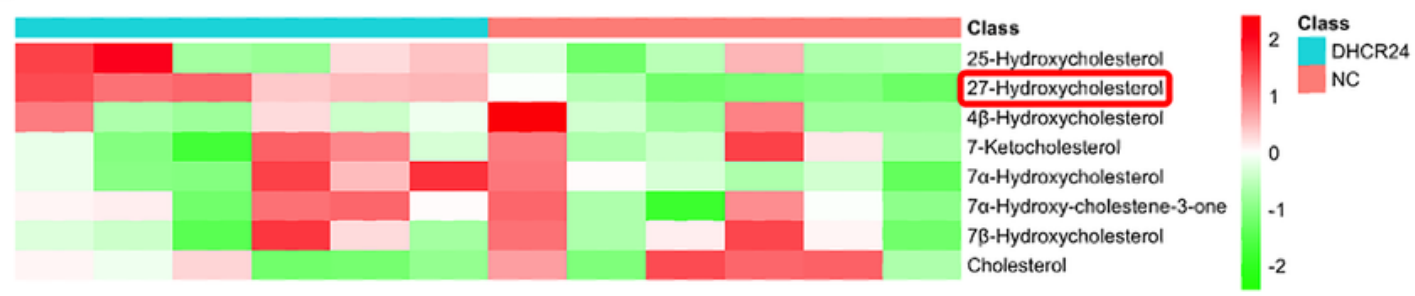

D

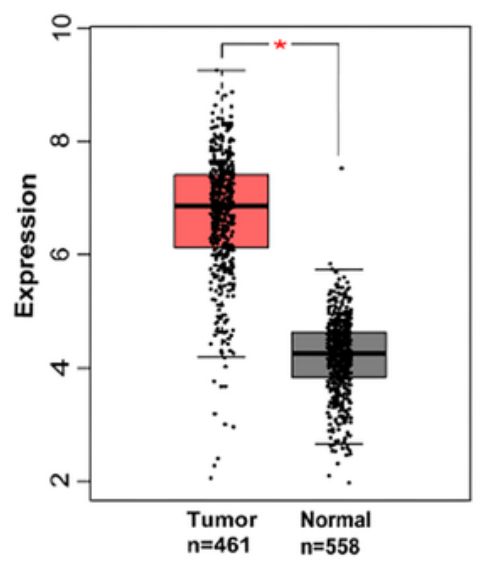

E

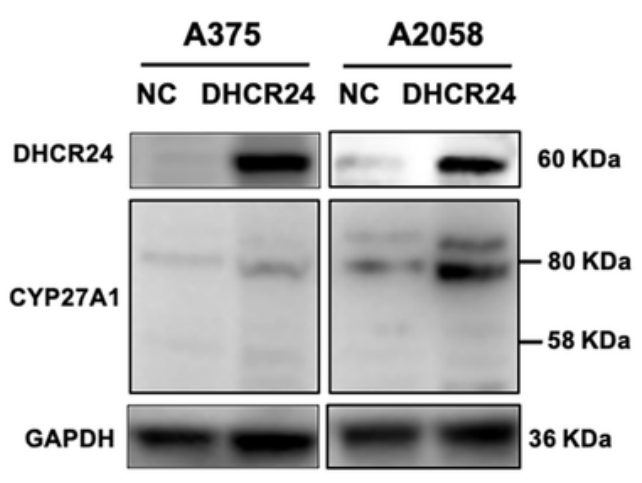




\section{Figure 4}

DHCR24 induced cellular 27-HC accumulation in melanoma cells. (A) DHCR24 catalyzes the synthesis of cholesterol by reducing the double bond at C24-C25 position of desmosterol. (B) A375 and A2058 melanoma cells were treated with multiple concentrations $(0,5,10$ and $50 \mu \mathrm{M})$ of cholesterol and ethanol as a control under the condition of tumorsphere formation for 7-10 days. Cell tumorspheres with diameter $>40 \mu \mathrm{m}$ were counted under $50 \times$ magnification objective lens. (C) The heatmap analysis for cholesterol metabolites. The heat map color codes reflect a change. (D) Expression levels of CYP27A1 in 1019 Skin Cutaneous Melanoma (SKCM) samples. (E) The levels of DHCR24 and CYP27A1 in A2058 melanoma

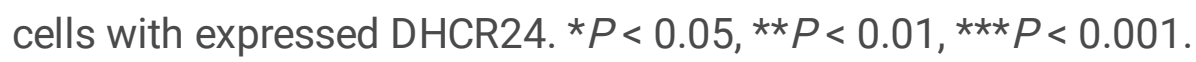


A

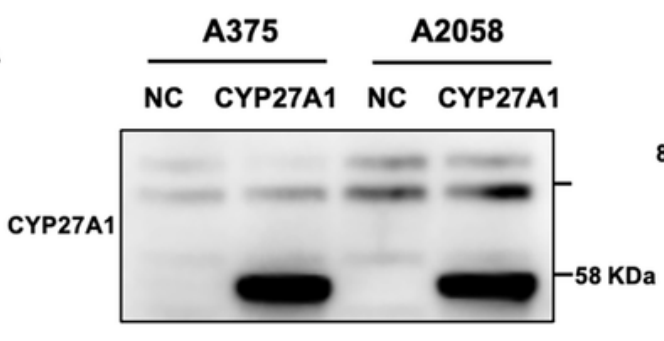

GAPDH

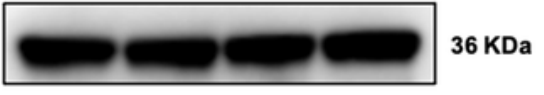

B

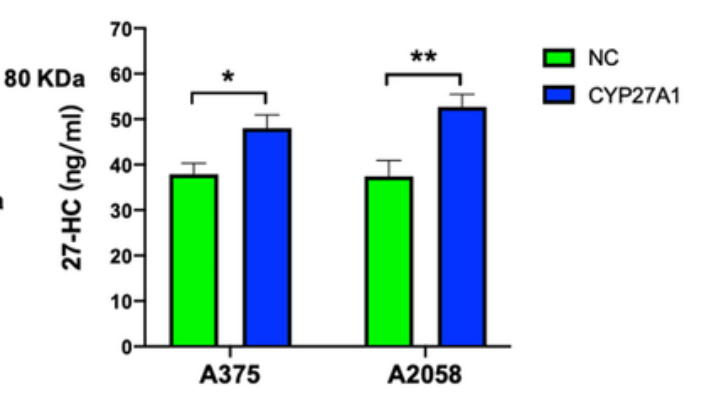

C

NC

CYP27A1

A375
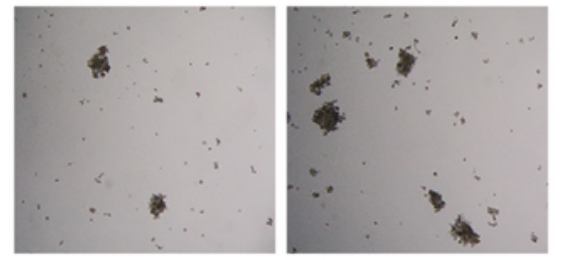

A2058
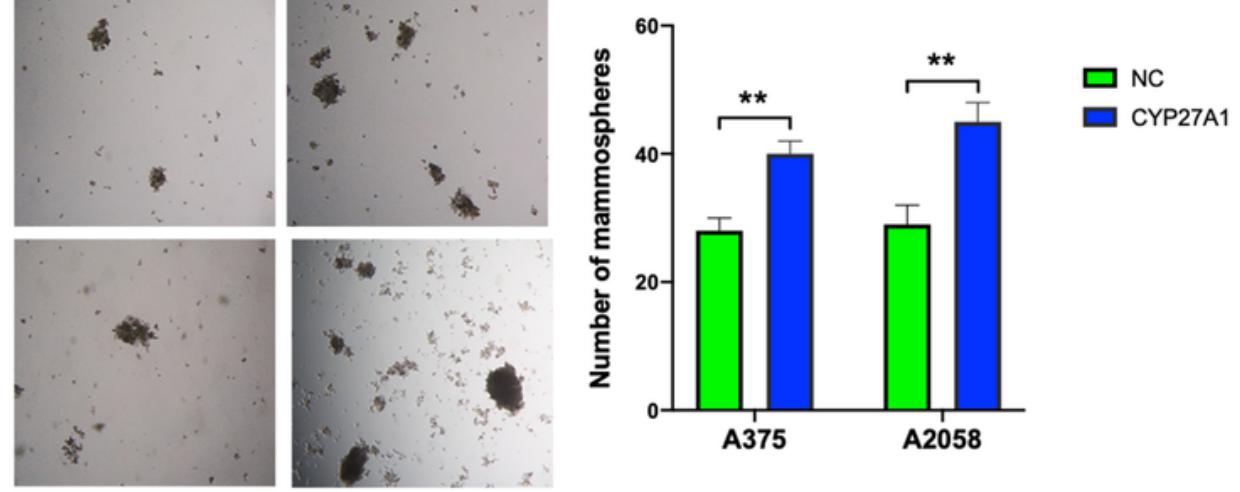

D
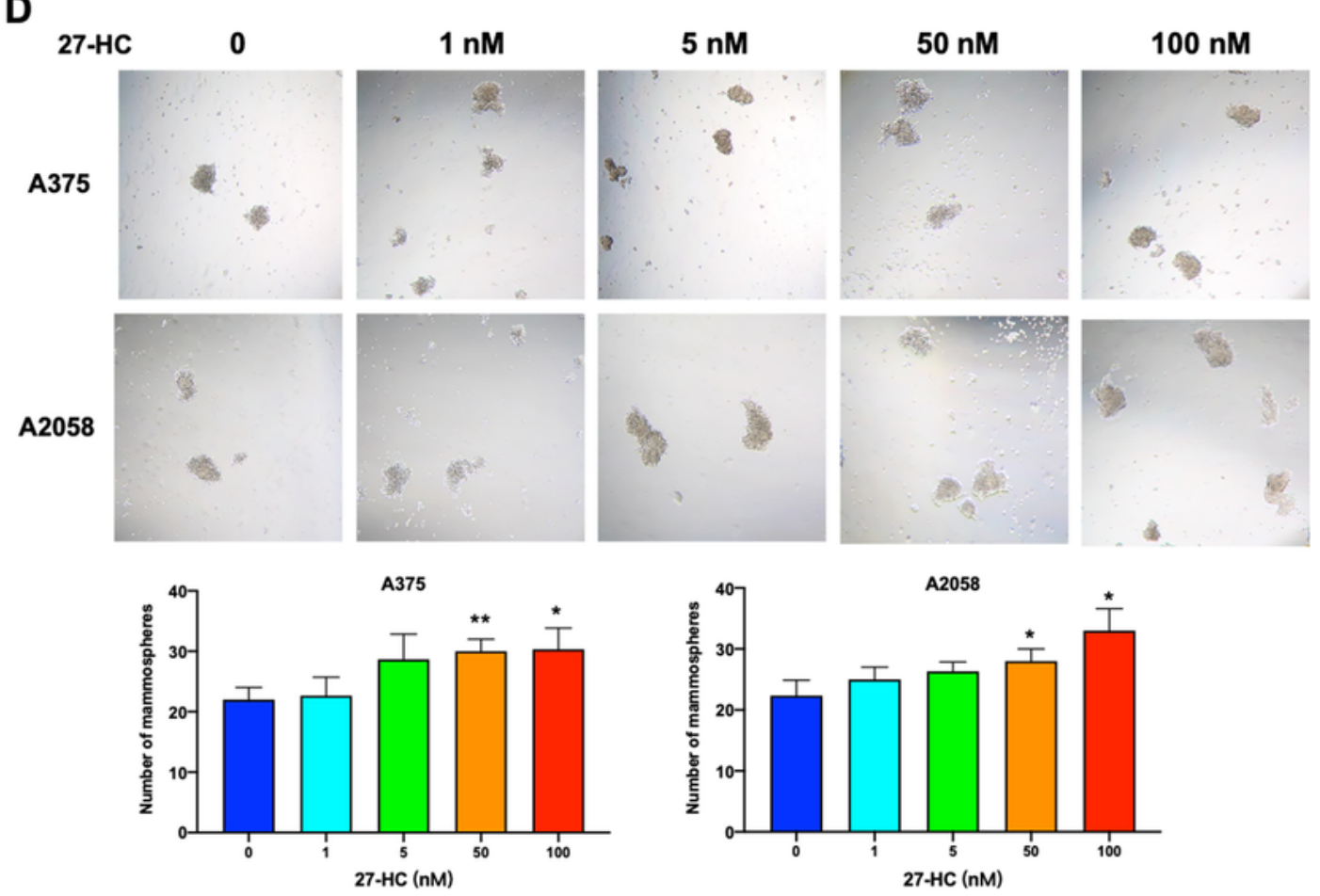

\section{Figure 5}

27-HC promotes the growth of melanoma stem-like cell populations in melanoma cells. (A) Overexpression of CYP27A1 in A375 and A2058 cells. (B) The levels of 27-HC in A2058 melanoma cells with CYP27A1 overexpression. (C) Tumorsphere formation in A375 and A2058 melanoma cells with overexpressed CYP27A1. Cell tumorspheres with diameter $>40 \mu \mathrm{m}$ were counted under $50 \mathrm{x}$ magnification objective lens. (D) A375 and A2058 melanoma cells were treated with multiple 
concentrations $(0,1,5,50$ and $100 \mathrm{nM})$ of $27-\mathrm{HC}$ and ethanol as a control under the condition of tumorsphere formation for 7-10 days. Cell tumorspheres with diameter $>40 \mu \mathrm{m}$ were counted under $50 \mathrm{x}$ magnification objective lens. ${ }^{\star} P<0.05,{ }^{\star} * P<0.01,{ }^{*} * * P<0.001$.

A

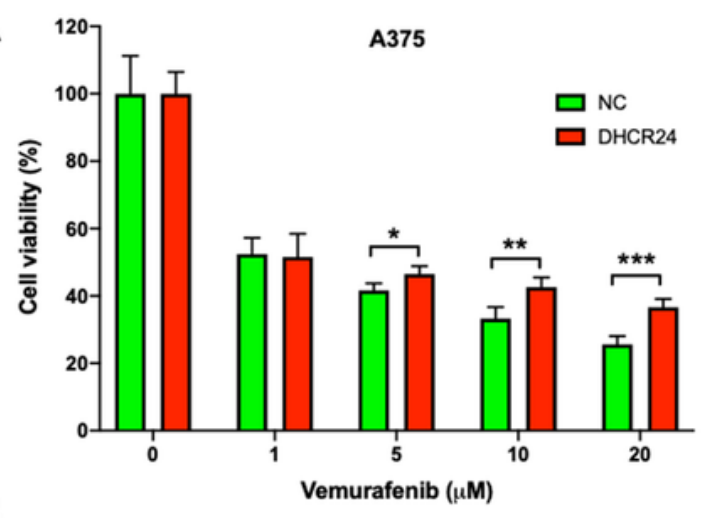

B

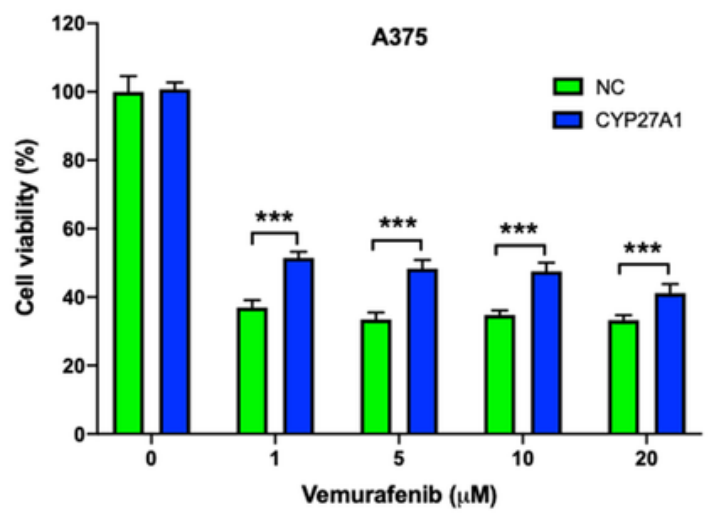

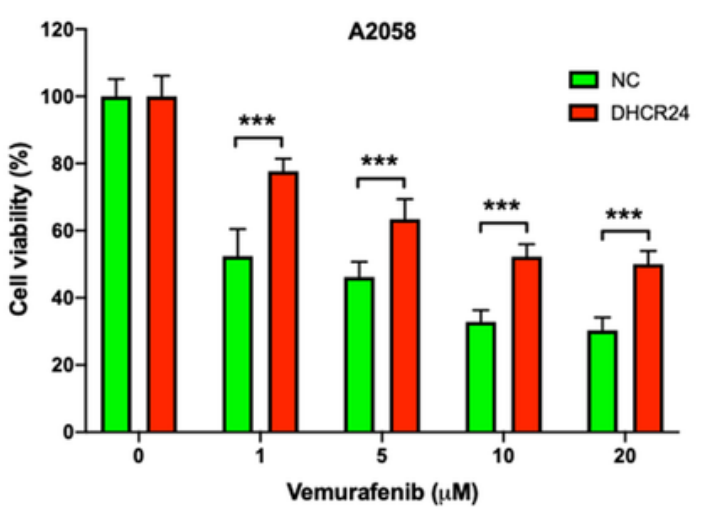

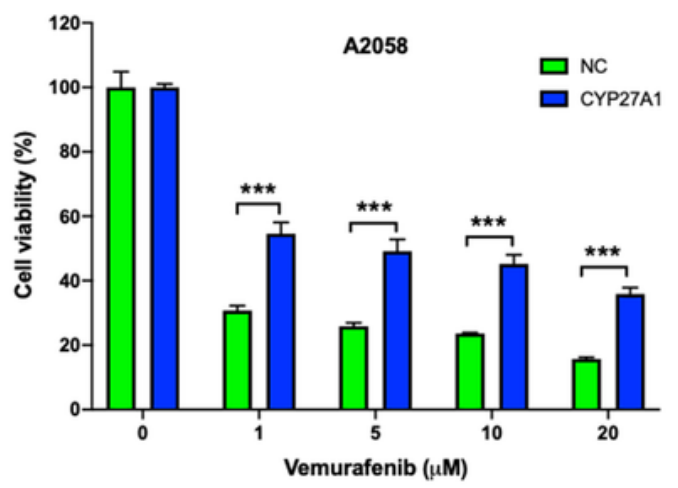

\section{C}
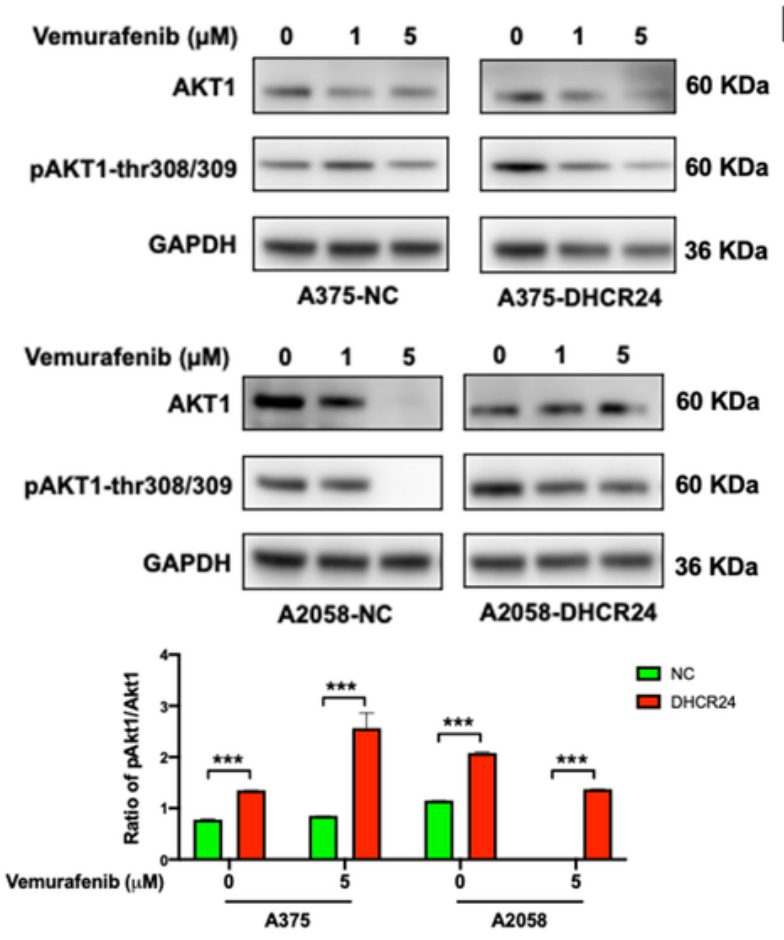

D

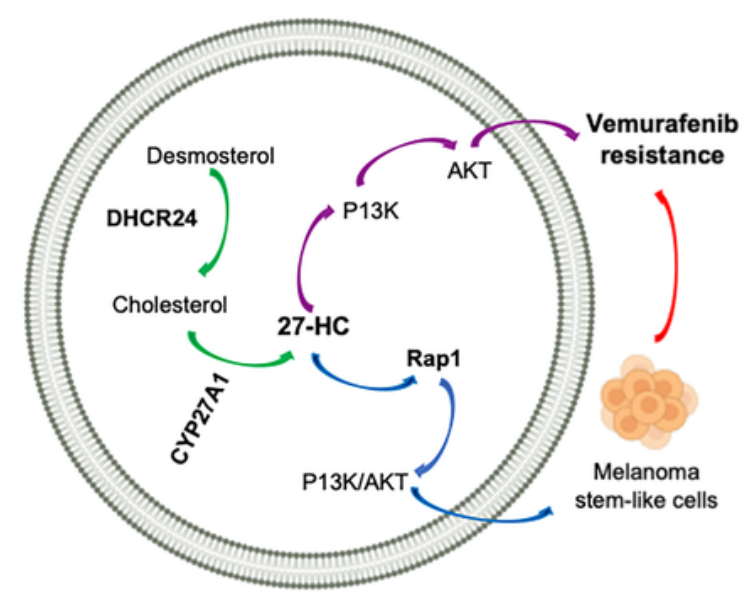

Figure 6 
DHCR24 contributes to vemurafenib resistance by accumulating cellular 27-HC and activating AKT pathway in melanoma cells. (A-B) Cell proliferation in A375 and A2058 melanoma cells with DHCR24 and CYP27A1 overexpression (vector as a control) were treated with multiple concentrations $(0,1,5,10$ and $20 \mu \mathrm{M}$ ) of vemurafenib and DMSO as a control for 2 days. (C) A375 and A2058 melanoma cells with DHCR24 overexpression were treated with multiple concentrations $(0,1,5,10$ and $20 \mu \mathrm{M})$ of vemurafenib and DMSO as a control at 2 days for detecting anti-AKT and anti-pAKT. (D) Schematic diagram showing the basic conclusion. ${ }^{*} P<0.05, * * P<0.01, * \star \star P<0.001$.

\section{Supplementary Files}

This is a list of supplementary files associated with this preprint. Click to download.

- SupplementaryTable.docx

- SupplementaryFigure.docx 